Article

\title{
Development of Ceramic Materials for the Manufacture of Bricks with Stone Cutting Sludge from Granite
}

\author{
Juan María Terrones-Saeta ${ }^{1, * \mathbb{C}}$, Jorge Suárez-Macías ${ }^{1}{ }^{\mathbb{D}}$, Francisco Antonio Corpas-Iglesias ${ }^{1} \mathbb{D}^{\mathbb{D}}$, \\ Valentyn Korobiichuk ${ }^{2}$ (D) and Volodymyr Shamrai ${ }^{2}$ (D) \\ 1 Department of Chemical, Environmental, and Materials Engineering, Higher Polytechnic School of Linares, \\ University of Jaen, 23700 Linares, Spain; jsuarez@ujaen.es (J.S.-M.); facorpas@ujaen.es (F.A.C.-I.) \\ 2 Department of Mining Named after Professor Bakka M.T., Zhytomyr Polytechnic State University, \\ 10005 Zhytomyr, Ukraine; korobiichykv@gmail.com (V.K.); vp97776@gmail.com (V.S.) \\ * Correspondence: terrones@ujaen.es; Tel.: +34-675-201-939
}

Received: 25 May 2020; Accepted: 7 July 2020; Published: 10 July 2020

\begin{abstract}
The manufacture of bricks for building purposes consumes large quantities of virgin materials, such as clay. On the other hand, the ornamental stone processing industry produces a huge amount of stone cutting sludge in its process. Therefore, this study presents the development of ceramic materials for the manufacture of bricks with stone cutting sludges, more specifically from granite. For this purpose, the physical properties of the stone cutting sludge and the chemical composition were mainly analyzed. Subsequently, different groups of ceramic samples were conformed and sintered with various combinations of clay and of stone cutting sludges. The conformed samples were evaluated with different physical tests and with the compressive strength test. The addition of stone cutting sludges to the ceramics reflected the creation of a material with lower density and higher porosity. The compressive strength of the different groups reflected a maximum allowable percentage of stone cutting sludges incorporation of $70 \%$. Therefore, ceramic materials were developed with stone cutting sludges, developing a sustainable, lighter material with acceptable mechanical and physical characteristics. Avoiding the deposition of a polluting waste in a landfill and at the same time avoiding the extraction of new virgin materials.
\end{abstract}

Keywords: stone cutting sludge; mining waste; ceramic; brick; clay; granite; sustainability; compressive strength; physical tests

\section{Introduction}

Sustainability, the reduction of environmental impact, and the search for more environmentally friendly solutions are the new trends on materials that are currently being imposed. This fact is fundamentally due to a greater environmental awareness of the population, a greater scarcity of resources, and consequently, more restrictive environmental regulations in the different countries [1,2].

A series of sustainable materials are currently being developed that produce a lower environmental impact and lower greenhouse gas emissions, mainly in the construction sector. It must be taken into account that the construction sector is one of the most polluting, since it consumes large quantities of raw materials [3], uses little optimized industrial processes, and manufactures enormous quantities of products [4]. These factors directly intervene in the future scarcity of essential raw materials [5], as well as in the consumption of energy, being the sector that produces the highest energy consumption worldwide [6].

In the construction sector, more specifically in building, a large amount of materials is consumed. The construction of new buildings or the renovation of existing buildings is proof of this fact. Among the 
most consumed materials are ceramics, and in turn bricks. Bricks are ceramic products with thousands of years of history and are commonly used for various reasons [7]. Among these reasons are their good mechanical behavior, economic costs, as well as durability [8]. However, for the manufacturing of this product, it is necessary to carry out expensive operations of extraction of virgin materials, such as clay, with the consequent emissions of $\mathrm{CO}_{2}$ [9]. A high temperature sintering process is also necessary, around $950{ }^{\circ} \mathrm{C}$. It is therefore a product that must suffer remodeling towards a more sustainable material, and on which various investigations have been carried out in order to find more environmentally friendly solutions [10-12].

In order to obtain a more sustainable ceramic product, several modifications have been made surrounding the formulation and process of brick manufacturing. On the one hand, countries as important as China have limited their production to avoid reducing the disappearance of cultivable areas [13]; however, stopping such an important sector that produces so many benefits to the population, as the construction sector, may not be the best solution. On the other hand, more sustainable materials have been developed, such as geopolymers, which use waste in their conformation and less polluting manufacturing processes $[14,15]$. However, it is a line of study still to be developed, and that must solve the problems of durability. Finally, other options for the manufacturing of ceramic bricks have been the incorporation of waste into its matrix, making processes more economical, and environmentally sustainable [16].

The addition of waste into ceramic materials for the manufacturing of bricks has been done with various wastes, resulting in several success cases $[17,18]$. The success of this technique is based on different factors; on the one hand, it reduces the amount of virgin material to be used, clay, reducing the operations of extraction of materials, the emissions that it entails, and the environmental impact on the territory. On the other hand, a currently unused waste is incorporated; thus, reducing the economic cost of the final product and, consequently, the layout of waste used in landfills is reduced. In addition, the integration of waste into ceramic materials can provide particular characteristics that benefit the final material. Among these characteristics are thermal and acoustic insulation [19,20], as well as the lightness of the material [21]. This inclusion is easy to carry out without executing great modifications in the production industry, either in the processes or in the machinery [22].

It is an option that brings economic and environmental benefits, reduces the deposition of materials in landfills, and provides a new life to the waste, and is, therefore, totally within the new circular economy [23]. Furthermore, it is common to find waste that, by its chemical composition, can seriously damage the environment, either by contaminating surface water or underground water, or by affecting vegetation and fauna. These wastes must be treated with special care and incorporate into materials that cause adequate retention of the elements or chemical compounds conflicting. In this case, the incorporation in ceramic materials of the contaminating residues is one of the best options, since the ceramic matrix retains these contaminants in high proportion, and avoids their leachate [24-26].

On the other hand, and also within the construction sector, the ornamental stone production industry produces in Europe an amount of approximately 5 million tons of stone cutting sludges per year [27]. This waste is produced directly in the labor of cutting the stone for its later treatment and sale. It has been calculated that the extraction and processing of granite and marble produce $40 \%$ in volume of stone cutting sludge with respect to the initial volume, being the $20 \%$ of this percentage corresponding to the labor of the processed in the industry [28]. Therefore, it is a waste produced in great quantity, and its uncontrolled deposition can create a series of environmental problems.

The cutting of the granite, on which this study is based, with a diamond disc for processing, is usually done with water to avoid heating the material and of the machinery. Therefore, stone cutting sludge is produced with a reduced particle size, around tens of micrometers, and with a series of metallic elements, such as cobalt or copper proceeding from of the cutting disc [29]. At the same time, it is common to find organic compounds coming from lubricants and fats of the machinery itself. Even if these stone cutting sludges are subjected to subsequent water separation by flocculation, percentages of flocculants are usually obtained, which is a very limiting factor for their reuse [30]. 
In short, stone cutting sludge is a waste that poses a problem in Europe. It is an even more serious problem in countries such as the Ukraine, where environmental regulations are less restrictive, and stone cutting sludge is landfilled directly in areas adjacent to the producing industry in large pits. These pits are not waterproofed in most cases and are be using for sediment deposition by their own gravity and water reuse. Therefore, these pits can cause significant contamination of agriculture, living beings, and surface water or groundwater [31].

Based on the above, the deposition of the stone cutting sludges in a landfill can cause the contamination of surface water and groundwater due to its chemical composition, as well as to a serious effect on vegetation due to its small particle size. It is a problem that has been tried to be solved through its reuse, and (always) by initially analyzing its chemical composition to study its viability. The main areas in which stone cutting sludges have been reused have been bank restoration [32], waterproofing, of substrates [33], or very specific work in civil construction [34]. In these operations, the chemical composition should be controlled, since a high proportion of elements that pollute would limit the use in the first two options, and should be studied in depth for the third option.

There are also isolated investigations in which these stone cutting sludges are incorporated as an additive to cement [35,36], to mortar [37], to concrete [38], to plaster mortar [39], or even manufacturing, such as artificial aggregates [40] or bituminous mixtures [41]. In most of the cases mentioned, mainly in cementitious materials, their incorporation directly affects the resistance characteristics of the final material [42].

According to what has been commented, and with the aim of providing an environmentally friendly solution that reduces the deposition of waste, and creates sustainable materials with an easy industrialization process, this work studies, the incorporation of granite cutting sludge in ceramic materials for bricks.

With this objective, stone cutting sludges was firstly analyzed, being an essential stage for the detection of the physical properties of the stone and its compatibility with clay. The chemical composition was studied to evaluate the influence that it could have on the final product and the existence of chemical elements that could become conflicting. Once the stone cutting sludge had been analyzed, different groups of samples were manufactured with different percentages of combination of clay and the stone cutting sludges, from 100\% clay to 100\% stone cutting sludge. These samples were sintered and then evaluated with various traditional physical tests on ceramics. These tests were carried out to analyze the variation in the properties of the ceramics with respect to the increase in the percentage of stone cutting sludge. The color of the samples was evaluated on the basis of the chemical composition, determining which factors were directly involved in the brightness and color reflected by the different families of samples. Finally, the compressive strength test, so limiting in the ceramic industry for the incorporation of waste, reflected the maximum percentage of stone cutting sludges in the ceramic.

\section{Materials and Methods}

\subsection{Materials}

The materials used in this project are common industry materials, taken directly from the producing companies without altering their characteristics. These materials are analyzed in the methodology, so their description in this section will be of their formation, origin, and general qualities.

A drying process was carried out to eliminate the water they contained, and provided, in the study, a greater control of all variables, among which included humidity. However, the existence of humidity in the factory during the manufacturing process would not harm the final material; it would simply have to be taken into account so as not to add excess water, and to respect the optimal combinations of materials provided by this study. Therefore, all the tests described in the methodology are carried out with dry materials and without moisture.

The materials used and the basis of this work are the clay and the stone cutting sludge. 


\subsubsection{Clay}

The clay used corresponds to the area of Jaen Spain. In this geographical area, there is an important and traditional industry of manufacturing bricks with red clay; the one used in this study.

The red clay was evaluated with various tests in the methodology; however, it should be noted that it has a high quality from its small particle size and presents no hazardous chemicals elements or organic matter.

The clay to be used in the study was sieved by the $0.25 \mathrm{~mm}$ sieve; thus, obtaining a material that can be easily processed in the mixture.

\subsubsection{Stone Cutting Sludge}

The stone cutting sludges used in this study belong to the companies producing ornamental stones located in the immediate of the city of Zhytomyr, Ukraine.

These stone cutting sludges are produced in the granite cutting process for the manufacture of different decorative elements. The use of water to prevent the heating of the machinery produces this stone cutting sludge. This stone cutting sludge is deposited in pits for the reuse of water after sedimentation and drying of the waste by natural evaporation processes. It has a reduced particle size due to its formation process.

The initial material from which it comes is very similar throughout the production process, as well as the machinery used. This fact is essential for the use of waste, since it directly implies that the physical and chemical characteristics of the stone cutting sludges remain constant over time, in different productions, and in different years. It is therefore easy to define a suitable material combination with this waste that is stable and should not be continuously varied with the properties of the waste. In other types of waste, such as sewage sludge, or construction and demolition waste, the same is not true, so it is difficult to define an optimal combination of materials.

The physical and chemical testing of stone cutting sludges is defined in the methodology.

\subsection{Methodology}

The methodology followed in this work consists of a series of logically ordered tests to evaluate the suitability of incorporating stone cutting sludges in ceramic materials. In this way, the critical processes can be identified, as well as the special care that must be taken to the objectives of the study.

Firstly, and as a basis for any study of waste incorporation, the physical and chemical characteristics of the initial materials were evaluated. To this end, tests were carried out to determine the chemical composition of both materials, as well as the physical properties that conditioned their mixing and the compatibility of them.

Subsequently, and having evaluated the suitability of the stone cutting sludges and clay for the manufacture of ceramics, different groups of samples were conformed with increasing percentages of the waste, from $100 \%$ clay to $100 \%$ stone cutting sludges. In this way, it was possible to obtain samples in all ranges of possibilities. These samples were conformed and sintered to later evaluate their physical properties.

Finally, and as a main limiting factor for the correct execution of ceramics, compressive strength tests were carried out. All of the groups of samples were tested, evaluating the influence of the compressive strength with the percentage of addition of stone cutting sludges. Based on this study, it was possible to obtain a maximum incorporation of stone cutting sludges in ceramics, as well as a wide range of possible combinations with different physical and resistance properties for particular cases.

This methodology is further detailed in the following four major blocks: analysis of the initial materials, conformation of samples and physical tests, color analysis and compressive strength testing. In turn, in the Results section, it is described in an analogous way to the scheme presented. 


\subsubsection{Analysis of Initial Materials}

The physical and chemical analysis of the properties of the starting material is fundamental to establish the criteria to follow in the study. This analysis provides information necessary for the evaluation of compatibility between materials, as well as of the presence of certain chemical elements that should be controlled. The characterization of waste is essential for its incorporation into a material, notably reducing the environmental impact with respect to its deposition in a landfill. For example, the use of waste with pollutants and elements that are harmful to the environment in landfill or filling in road infrastructure does not imply effective reuse, since its leaching can produce greater pollution of groundwater than deposition in a landfill. Therefore, a characterization task is required that will condition the viability of the incorporation of the waste in a new material or process.

The physical tests carried out surrounding clay and the stone cutting sludges are the particle density tests, according to the standard UNE-EN 1097-7, and the plasticity index, according to the standards UNE 103103 and UNE 103104. The density of the particles was calculated by the pycnometer method, with successive measurements of weight and volumes in water of the sample. On the other hand, plasticity is essential in materials for ceramics, reflecting their malleability, as well as the percentage of clayey particles in the materials. The calculation of the plasticity index is made by the Casagrande method, evaluating the liquid limit with the Casagrande cup and the plastic limit by the appropriate method. Both tests accurately identify the compatibility between the clays and the stone cutting sludges, as well as the possible volumetric corrections, if the density between the two materials were very different.

Once the physical properties were evaluated, the chemical characterization of both materials was carried out. For this purpose, elemental analysis tests were performed with the TruSpec Micro equipment of the LECO brand (LECO, St. Joseph, MI, United States), loss on ignition, and X-ray fluorescence with the ADVANT' $\mathrm{XP}+$ equipment of the Thermo Fisher brand (Thermo Fisher Scientific, Waltham, MA, United States).

The elemental analysis test detects the percentage of carbon, nitrogen, hydrogen, and sulfur present in the sample. For this purpose, the sample is combusted and the gases from combustion are analyzed. In turn, the loss on ignition reflects the loss of weight after subjecting the sample to the temperature of $1000 \pm 10{ }^{\circ} \mathrm{C}$, reflecting the percentage of organic matter or carbonates present in the sample. The loss of weight may also be due to the transformation of some chemical compounds or the oxidation of some chemical elements. This is an essential test for ceramic raw materials, as the temperature is similar to that of the sintering process, and represents the properties of the final material. The X-ray fluorescence test identifies the elemental composition of the samples analyzed, showing the inorganic composition of the materials in a quantitative method.

With the defined tests, it will be possible to evaluate the existence of harmful chemical elements, elements that will condition the final product, or the physical properties that will define the compatibility between materials. In this way, the suitability of the use of stone cutting sludges in ceramics can be assessed.

\subsubsection{Sample Conformation and Physical Tests}

After evaluating the suitability of the initial materials, different groups of samples were conformed with percentages of clay and the stone cutting sludges. The initial group is composed of samples with only clay. This group was made to be able to easily compare the properties of ceramics with stone cutting sludges in different percentages with respect to the traditional material, evaluating the variations of the physical and mechanical properties. Subsequently, different groups of samples were executed with progressive percentages of clay substitution by stone cutting sludge of $10 \%$, until the last group of samples with $100 \%$ stone cutting sludges was obtained. In this way, groups of samples were obtained that were uniformly distributed in all possible combinations of clays and stone cutting sludges. The composition of the different groups of samples conformed is described in Table 1. 
Table 1. Conformed ceramics families with combined percentages of clay and the stone cutting sludge.

\begin{tabular}{ccc}
\hline Samples Groups & Clay, $\%$ & Stone Cutting Sludge, $\%$ \\
\hline 0S10C & 100 & 0 \\
1S9C & 90 & 10 \\
2S8C & 80 & 20 \\
3S7C & 70 & 30 \\
4S6C & 60 & 40 \\
5S5C & 50 & 50 \\
6S4C & 40 & 60 \\
7S3C & 30 & 70 \\
8S2C & 20 & 80 \\
9S1C & 10 & 90 \\
10S0C & 0 & 100 \\
\hline
\end{tabular}

The test samples from each group were conformed according to the same procedure. In the first place, both elements, clay and stone cutting sludges, were mixed in the corresponding percentages according to the family. Later, they were homogenized and $10 \%$ of water was added, referred to the percentage by mass of the dry mixture, and they were mixed again. It should be noted that the percentage of water added has been empirically evaluated as the most suitable for this type of material and compacting process, higher percentages causing water exudation and lower percentages leading to lower density and, therefore, lower compressive strength. The mixture of the materials mentioned above was conformed in a steel matrix with internal dimensions of $60 \mathrm{~mm}$ in length and $30 \mathrm{~mm}$ in width, obtaining samples of similar proportions. The compaction was carried out with an automatic test press model AG-300kNX of the commercial brand Shimadzu (Shimadzu, Kyoto, Japan). This conformation was executed at a constant speed until the maximum compaction stress was reached, $50 \pm 1 \mathrm{MPa}$, this tensile was maintained for $1 \mathrm{~min}$, and the matrix was removed from the test press. The samples conformed by this method reflect similar values to the materials made in industry, as well as those made by extrusion.

Subsequently, samples of the different groups were then dried at a temperature of $105 \pm 2{ }^{\circ} \mathrm{C}$ for $24 \mathrm{~h}$ to gradually remove the excess water and prevent the formation of cracks during the sintering process. These dried samples were measured and weighed for the subsequent tests.

The sintering of the samples was carried out in the muffle furnace after all the samples had been introduced. The temperature was raised to 4 degrees Celsius per minute from room temperature to $950 \pm 10^{\circ} \mathrm{C}$. This temperature was maintained for one hour and the specimens were cooled down again at the same rate.

The sintered pieces were subjected to a series of standardized tests for the calculation of their physical properties, tests that are essential in the field of ceramic materials for bricks. These tests are to determine weight loss, linear shrinkage (UNE-EN 772-16 standard), capillary water absorption (UNE-EN 772-11 standard), cold water absorption (UNE-EN 772-21 standard), open porosity, and bulk density (UNE-EN 772-4 standard).

Variations in the weight of different samples before and after the sintering process reflect the linear shrinkage and weight loss of the samples. Both phenomenon are very common in ceramics and must be controlled and limited. The performance of these tests on all groups of samples accurately reflected how both characteristics vary with the percentage of stone cutting sludges. On the other hand, the capillary water absorption test consists of partially immersing the sample in water at room temperature for a short time of $1 \mathrm{~min}$, then weighing it and calculating this ratio by mass differences. It is therefore a test that perfectly reflects the connection between the pores of the ceramic material; a characteristic that has a significant influence on other properties, such as thermal or acoustic insulation.

In turn, the cold water absorption test consists of completely immersing the samples for a prolonged period of $24 \mathrm{~h}$. After this time, the samples are weighed again and compared with the dry 
weight, determining the water absorption. The test thus reflects the absorption capacity of the ceramic, a fundamental fact to take into account when these ceramic elements are outdoors.

Finally, the open porosity and bulk density test is calculated through three types of measurements of the weight of the samples, the dry weight, the water absorption weight and the submerged weight, for these calculations it is obviously essential to use hydrostatic balances. From standardized ratios and taking the density of water with respect to the test temperature, the open porosity and bulk density were calculated. These properties of the ceramics have a significant influence on several fundamental properties, like as, including strength, lightness of the material, thermal insulation, acoustic insulation, etc. Therefore, it is essential to study the variation of these properties with the percentage of addition of stone cutting sludges.

\subsubsection{Color Analysis}

Color is one of the characteristics of ceramics. This characteristic, not limited by the normative, is limited by the ceramic industry. The quality processes in industry limit the maximum permissible variations in color in the manufactured elements. In this way, the bricks will create similar tonalities in the construction. It is therefore a very important factor to take into account, and not negligible.

A waste product that, when added to the ceramic material, creates a material with acceptable physical and mechanical properties, but which varies abruptly in color, would be rejected in most industrial processes.

Based on what has been said, the color variation should be studied and the reasons why it occurs should be evaluated. Mainly, the color variation of ceramics is produced by their chemical composition, provided that the forming and sintering process of the ceramic is similar. Therefore, this section will present the image of the samples and reflect a study of why color variation occurs, determining those chemical compounds present in the most influential stone cutting sludge.

Then, and in this respect, in order to determine subjectively the color of the different families of ceramics, the color coordinates of each family in the primary colors (red, green, and blue) will be measured with the colorimeter (RGB-2, PCE, Meschede, Germany). In this manner, the color of the different ceramics manufactured with increasing percentages of stone cutting sludge can be graphically reproduced, and to determine whether they are acceptable by the production industry.

\subsubsection{Compressive Strength Test}

Brick is a ceramic product of unparalleled use in building construction because of the characteristics mentioned above and also because of its resistance. In other words, the mechanical resistance of the ceramic material is one of the fundamental properties that the product must provide and it is limited by the European regulations in this respect.

The compressive strength test was carried out with an automatic test press that continuously recorded the values of stress and deformation of the sample, detecting the point of collapse of the sample. To carry out the test, the samples were dried and then tested in the aforementioned press at room temperature. The test was carried out at a constant speed of stress per second, being performed in the same way for all the conformed samples of the different groups, according to the mentioned standard.

The European standard in this respect sets the minimum strength below which the material is considered rejectable, at $10 \mathrm{MPa}$. Consequently, the ceramic families that show resistance lower than that mentioned will be rejected, establishing the limit of incorporation of stone cutting sludges in the ceramic. On the other hand, the families of samples with results above the limit established by the regulations will be considered acceptable and susceptible to being used for the manufacture of bricks. 


\section{Results and Discussion}

\subsection{Analysis of Initial Materials}

The initial materials, clay and stone cutting sludges, were analyzed for their characterization. First, the particle density of both materials was calculated, with a density of $2573 \pm 55 \mathrm{~kg} / \mathrm{m}^{3}$ for stone cutting sludges and $2456 \pm 51 \mathrm{~kg} / \mathrm{m}^{3}$ for clay. Both values are very similar, so there is a good combination of them without dosage or homogenization problems. If, in addition, some of them have a much lower or higher density, proportioning by volume should be made and ensure that during their mixing no separation of them occurs.

Furthermore, the calculation of the plasticity index of both materials is essential for the identification of clayey particles. The clay as expected reflected a plasticity index value of $16.4 \pm 0.8 \%$. This result perfectly reflects the plastic behavior of the material, usual in the red clays used in the manufacture of bricks and acceptable for use. However, the stone cutting sludges reflected a plasticity index of $3.2 \pm 0.8 \%$, that is, even being the particle size of the order of the clays their plasticity index reflects the behavior of a material with low plasticity; therefore, its use would not imply problems of expansiveness in civil works. For this study, the non-plastic behavior of the stone cutting sludges is sufficient and acceptable for its use.

Once the physical properties have been analyzed, the chemical analysis of both materials is carried out. The elemental analysis determines the percentage of carbon, nitrogen, hydrogen, and sulfur that exists in the sample. This analysis, being the clay and the stone cutting sludges inorganic materials, represented a very low percentage of the elements. The results of the elemental analysis of clay and the stone cutting sludges are shown in Table 2.

Table 2. Elemental analysis carbon, hydrogen, nitrogen, and sulfur of clay and the stone cutting sludge.

\begin{tabular}{ccccc}
\hline Samples & Nitrogen, $\%$ & Carbon, $\%$ & Hydrogen, $\%$ & Sulfur, $\%$ \\
\hline Clay & $0.04 \pm 0.00$ & $1.16 \pm 0.05$ & $0.65 \pm 0.02$ & $0.00 \pm 0.00$ \\
Stone Cutting Sludge & $0.00 \pm 0.00$ & $0.46 \pm 0.01$ & $0.00 \pm 0.00$ & $0.00 \pm 0.00$ \\
\hline
\end{tabular}

As can be seen in Table 2, clay has a very low percentage of carbon. This result reflects the quality of the clay, therefore there is no organic matter or carbonates in important percentages that could damage the manufactured ceramic. The reduced value of hydrogen is due to the transformation of the hydrated compounds present in the clay. On the other hand, the elemental analysis of the stone cutting sludges shows a zero value of nitrogen, hydrogen, and sulfur. These results are excellent if their incorporation into ceramic materials is sought. The low percentage of carbon reflects different aspects. On the one hand, there is not a high proportion of organic matter; secondly, there is not a high percentage of carbonates (logical, as it is a residue of granite); thirdly, in the stone cutting sludges are no traces of fats or organic lubricants used in the cutting machinery that could derivate to the waste. Therefore, this test clearly reflects the chemical aptitude in relation to the mentioned elements for the conformation of the ceramics. The zero value of sulfur in both samples is noteworthy and very important. Sulfur is a pollutant element that must be controlled in the conformation for building materials. If sulfur had appeared in considerable quantities in the waste, the manufactured ceramic materials could produce polluting leachate.

In turn, the loss on ignition of clay and the stone cutting sludge samples reflect the variation in mass suffered by the heating of the sample to the temperature a $1000 \pm 10^{\circ} \mathrm{C}$. This mass variation can be due to several factors, the existence of organic matter, the existence of carbonates, the transformation of some chemical compounds, or the oxidation of some chemical elements. It is therefore difficult to differentiate which of the previous aspects it proceeds, but if should be taken into account for its limitation. Table 3 details the results of loss on ignition of clay and the stone cutting sludges. 
Table 3. Loss on ignition of clay and the stone cutting sludge.

\begin{tabular}{cc}
\hline Sample & Loss on Ignition, \% \\
\hline Clay & $7.90 \pm 0.35$ \\
Stone Cutting Sludge & $0.70 \pm 0.01$ \\
\hline
\end{tabular}

The loss on ignition of the clay reflects a low percentage, mainly due to the transformation of compounds, mainly because they are hydrated chemical compounds. It is common to find this type of value for clay used in brick making. On the other hand, the almost zero loss on ignition of stone cutting sludges is another example of its composition. This test corroborates the results obtained in the elemental analyses; there are no high percentages of organic matter, fats, or carbonates in the sample. It must be taken into account that these stone cutting sludges come from granite, and that granite is a rock composed mainly of quartz, feldspar, and mica, minerals with much higher processing temperatures than those of this test and of by a sintering process (therefore appear unaltered).

Finally, X-ray fluorescence analysis reflected all the chemical elements with the highest atomic weight present in the samples. The results of the $\mathrm{X}$-ray fluorescence assays for the clay and the stone cutting sludges are shown in Table 4.

Table 4. X-ray fluorescence of the clay and the stone cutting sludge samples.

\begin{tabular}{ccc}
\hline Compound & Clay, wt $\%$ & Stone Cutting Sludge, wt $\%$ \\
\hline $\mathrm{SiO}_{2}$ & $52.62 \pm 0.25$ & $65.80 \pm 0.24$ \\
$\mathrm{Al}_{2} \mathrm{O}_{3}$ & $17.83 \pm 0.19$ & $15.17 \pm 0.18$ \\
$\mathrm{Fe}_{2} \mathrm{O}_{3}$ & $7.84 \pm 0.13$ & $4.35 \pm 0.10$ \\
$\mathrm{~K}_{2} \mathrm{O}$ & $5.63 \pm 0.12$ & $4.25 \pm 0.10$ \\
$\mathrm{MgO}$ & $3.44 \pm 0.09$ & $1.56 \pm 0.06$ \\
$\mathrm{CaO}$ & $3.19 \pm 0.09$ & $3.55 \pm 0.09$ \\
$\mathrm{TiO}_{2}$ & $0.769 \pm 0.038$ & $0.579 \pm 0.029$ \\
$\mathrm{Na}_{2} \mathrm{O}$ & $0.165 \pm 0.015$ & $3.44 \pm 0.09$ \\
$\mathrm{P}_{2} \mathrm{O}_{5}$ & $0.154 \pm 0.008$ & $0.1750 \pm 0.0087$ \\
$\mathrm{MnO}_{\mathrm{ZnO}}$ & $0.154 \pm 0.008$ & $0.0623 \pm 0.0031$ \\
$\mathrm{~V}_{2} \mathrm{O}_{5}$ & $0.0379 \pm 0.0049$ & $0.0236 \pm 0.0027$ \\
$\mathrm{SrO}_{\mathrm{RuO}}$ & $0.0357 \pm 0.0031$ & - \\
$\mathrm{Rb}_{2} \mathrm{O}$ & $0.0344 \pm 0.0036$ & $0.0499 \pm 0.0025$ \\
$\mathrm{PdO}_{\mathrm{S} O}$ & $0.0318 \pm 0.0021$ & - \\
$\mathrm{S}$ & $0.0273 \pm 0.0048$ & - \\
$\mathrm{SO}_{3}$ & $0.0273 \pm 0.0040$ & - \\
$\mathrm{NiO}$ & $0.0247 \pm 0.0013$ & - \\
$\mathrm{PtO}_{2}$ & $0.0184 \pm 0.0039$ & - \\
$\mathrm{Cr}_{2} \mathrm{O}_{3}$ & $0.0164 \pm 0.0023$ & - \\
$\mathrm{Cl}$ & $0.0095 \pm 0.0008$ & - \\
$\mathrm{Co}_{3} \mathrm{O}_{4}$ & $0.0078 \pm 0.0023$ & $0.0655 \pm 0.0037$ \\
$\mathrm{MoO}_{3}$ & $0.0063 \pm 0.0018$ & - \\
$\mathrm{ZnO}_{\mathrm{As}_{2} \mathrm{O}_{3}}$ & $0.0062 \pm 0.0027$ & - \\
& - & $0.0917 \pm 0.0190$ \\
\hline
\end{tabular}

The X-ray fluorescence of the clay reflects a typical composition of an aluminum silicate, so high percentages of silicon oxide and aluminum oxide are present. In turn, iron oxide is also present, giving it the characteristic reddish color after sintering. Potassium oxide present in the sample is derived from feldspars present in the clay (as is calcium oxide). Low percentages of calcium oxide and magnesium oxide are found in the sample; these chemical compounds must be monitored in order to obtain good features of ceramic material. The other chemical elements present are in low proportion, so that the integrity of the material is assured. 
On the other hand, the chemical composition of the stone cutting sludges reflects an excellent chemical compatibility with the clay, since it contains minerals in its formation. As granite is the material from which these sludges come, the existence of chemical compounds derived directly from it is evident. High percentages of silicon oxide and aluminum oxide are present, and are derived from quartz, feldspars, and mica, i.e., the base of this rock belongs to an aluminum silicate. Feldspars, on the other hand, contribute the oxides of sodium, potassium, and calcium to the chemical composition. These elements are found in reduced proportion, so as in the case of clay, they do not harm the final material. The existence of mica in granite is reflecting by silicon oxide and aluminum oxide, but more specifically by magnesium oxide and iron oxide. That is to say, the chemical composition of the stone cutting sludges practically coincides with that of a granite, with no chemical elements, such as heavy metals, coming in large part from the abrasion of the cutting disc.

It is worth noting the low proportion of sulfur and arsenic in both clay and the stone cutting sludges. Both elements are highly controlled by environmental regulations and must be monitored in the final product through leaching methods, so that they are within the margins established by the regulations and do not produce environmental pollution. Neither are there heavy metals in great proportion that suppose a limitation-a reason why the low content in metals will be perfectly retained in the created ceramic matrix.

The results of the initial characterization of the materials have reflected an adequate compatibility between clay and the stone cutting sludges. The density of both materials is very similar (by avoiding mixing problems); in turn, the chemical composition of both materials is relatively the same, upon leaving to start from similar minerals, but with particular characteristics that will influence the results significantly (mainly, the higher transformation temperature of the different chemical compounds of the granite with respect to the clay).

\subsection{Sample Conformation and Physical Tests}

Once the suitability of the stone cutting sludges for the manufacture of ceramic materials has been conformed, as well as the clay, the different groups of samples detailed in Table 1 are shaped and sintered. These samples were executed according to the procedure detailed in the methodology and were subsequently characterized by various physical tests. Figure 1 shows the results of the weight loss and linear shrinkage tests on the groups of samples after sintering and according to the percentage of stone cutting sludges they contain.

The weight loss tests for the different groups of samples after sintering reflect the values expected and shown in the loss on ignition tests for clay and the stone cutting sludges. It is easily observable how the 0S10C family, formed only with clay, shows a loss of weight similar to that reflected in the loss on ignition test, as is the case with the family of samples 10S0C, conformed only with stone cutting sludges. Intermediate values show a linear variation corresponding to percentages of stone cutting sludges as a variable.

On the other hand, the linear shrinkage of the family composed only of clay shows a result of $2.71 \%$, decreasing progressively until the 5S5C family with $50 \%$ of stone cutting sludges that presents a value of approximately zero linear shrinkage. Higher values of stone cutting sludges in the ceramic reflect expansion of the ceramic. In other words, an increase in the percentage of stone cutting sludges reduces the linear shrinkage until to get cause dilatation. This fact is due to different reasons, firstly the particle size. The very small particle size of the clays causes the particles to be in contact and when the temperature rises, they join together in a resistant structure that reduces the size of the final piece. Therefore, the stone cutting sludges, even having a small particle size very similar to that of clay, does not have such a high specific surface area value, so this linear shrinkage does not occur. In addition, the weight loss test showed that although the waste and the clay have very similar chemical composition, the processing temperature of the chemical compounds of both elements is clearly different. Therefore, in the stone cutting sludges, there is no such binding of particles during sintering produced in the clay and the shrinkage values are not similar. 
(a) WEIGHT LOSS

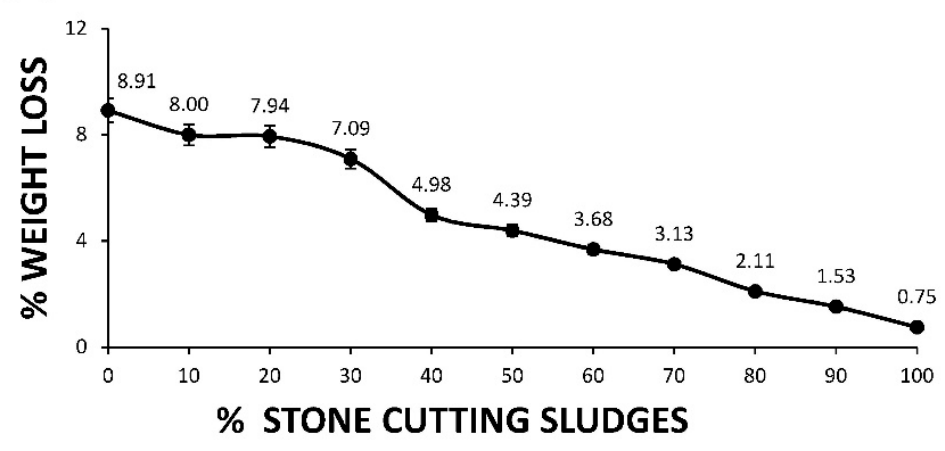

(b) LINEAR SHRINKAGE

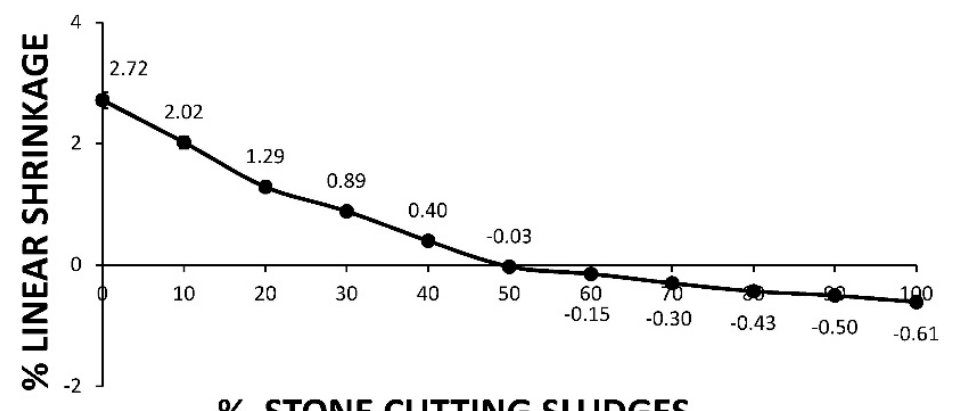

\% STONE CUTTING SLUDGES

Figure 1. Graphs of the physical tests of the different groups of ceramic samples as a function of the percentage of stone cutting sludges. (a) Weight loss after sintering and (b) linear shrinkage after sintering.

Both tests reflect clear results and that will condition all subsequent trials, so it is essential to take them into account. However, the values obtained in both tests in all the sample groups do not exceed the limits of the standards for ceramics for brick manufacturing.

The tests of capillary water absorption and cold water absorption detailed in the methodology are represented graphically in Figure 2, according to the percentage of stone cutting sludges present in the ceramic.

The capillary water absorption increases as the percentage of stone cutting sludges in the ceramic increases; however, the increase is low and does not represent a rejectable value (corresponding to the 10S0C family with $100 \%$ of the stone cutting sludges) due to the normative. This fact is mainly due to the reduction of the linear shrinkage of the ceramic that was previously noticed, creating a material with a more open structure and with a greater number of connected pores. Therefore, partially submerging the ceramic in water makes it possible for the water to be more easily introduced into more open structures with higher percentages of stone cutting sludges. Is a factor to be considered in other secondary characteristics, such as thermal and acoustic conductivity.

In turn, cold water absorption or room temperature water absorption shows similar results; a higher percentage of stone cutting sludge directly induces a higher percentage in the cold water absorption. This fact will condition the density and the porosity of the ceramic as it was later determined. However, it should be noted that the percentage of variation is very low, the change being much more abrupt with other types of wastes.

These characteristics of the ceramics directly reflect the behavior of the material when it is outdoors; a greater absorption, either by capillarity or in cold water, reflects that the material will retain more water in contact with it and, consequently, it will become a greater weight in the structure that supports such material. However, the emphasis is on again that the variations, although appreciable, are minimal. 


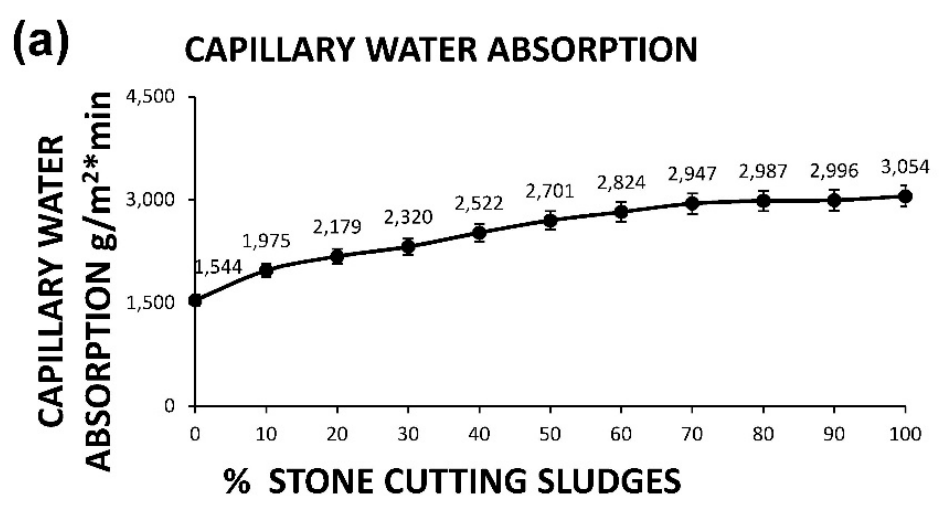

(b) COLD WATER ABSORPTION

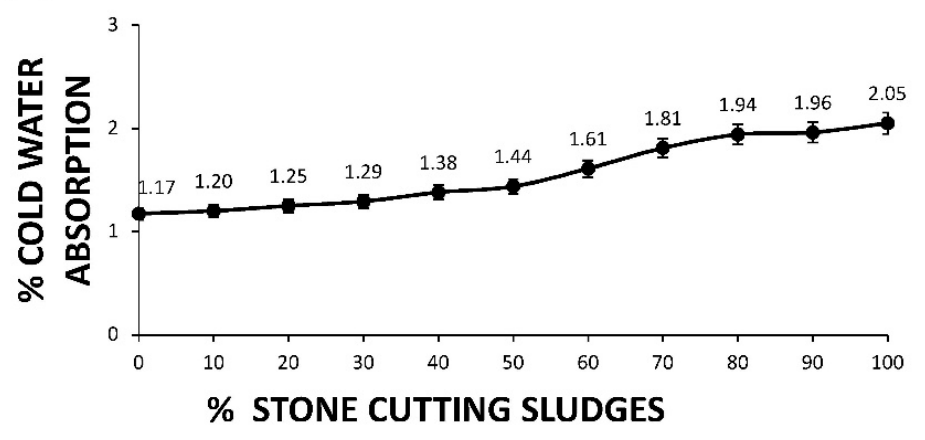

Figure 2. Graphs of the physical tests of the different groups of ceramic samples as a function of the percentage of stone cutting sludges. (a) Capillary water absorption and (b) cold water absorption.

Figure 3 shows the open porosity and bulk density tests of the different groups of ceramics conformed with up of increasing percentages of stone cutting sludges.

The open porosity, as have been can predicted in the previous tests, increases as the percentage of stone cutting sludges in the ceramics increases. As mentioned above, the smaller particle size of the clays and the processing temperatures of the chemical compounds in the stone cutting sludges result in less linear shrinkage of the ceramic and less weight loss after sintering, thus enabling a more open structure with a larger number of pores to be created. However, this higher porosity, if the appropriate mechanical and physical characteristics are maintained, should not be a problem. A higher porosity conditions a better thermal and acoustic insulation. This insulation characteristic is very important, since it means less energy consumption in the climate equipment, and in essence, reduces $\mathrm{CO}_{2}$ emissions. In other words, not only must sustainability be taken into account in the production of the material, but also in its entire life cycle analysis, which is why this increase in porosity can become very interesting.

Moreover, the bulk density diminishes as the percentage of sludges increases; this fact can be expected for all of the explained above concerning the different tests. As in the previous case, the decrease in density need not be a problem as long as other characteristics, such as the resistance, are maintained. A lower density creates a lighter material, which directly influences a lower load in the structure and, consequently, less use of structural materials.

Reducing the porosity of waste may be done by increasing the temperature to $1150{ }^{\circ} \mathrm{C}$. At this temperature is a large amount of melt (more than 65\%) with relatively low viscosity and high activity [43].

It should be noted that the values of all the families for the tests carried out are acceptable and provide very interesting particular characteristics; therefore, the compressive strength test will be responsible for determining the maximum percentage of stone cutting sludge addition in the ceramic acceptable. 
(a) OPEN POROSITY

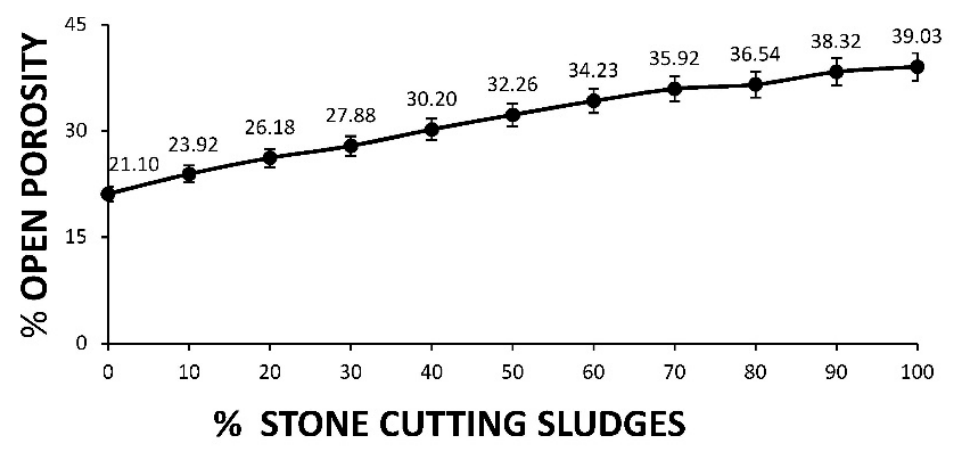

(b) BULK DENSITY

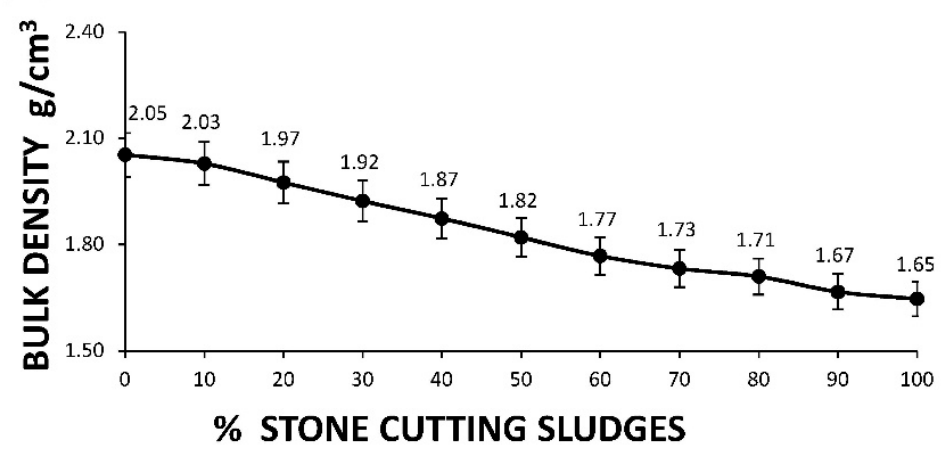

Figure 3. Graphs of the physical tests of the different groups of ceramic samples as a function of the percentage of stone cutting sludges. (a) Open porosity and (b) bulk density.

\subsection{Color Analysis}

As the granite sludge content increased, the samples changed color from red-brown to light red, as shown in Figure 4. The first sample on the left does not contain granite sludge. Moreover, $10 \%$ more granite sludge was added to each subsequent sample. The last sample contains $100 \%$ granite sludge.

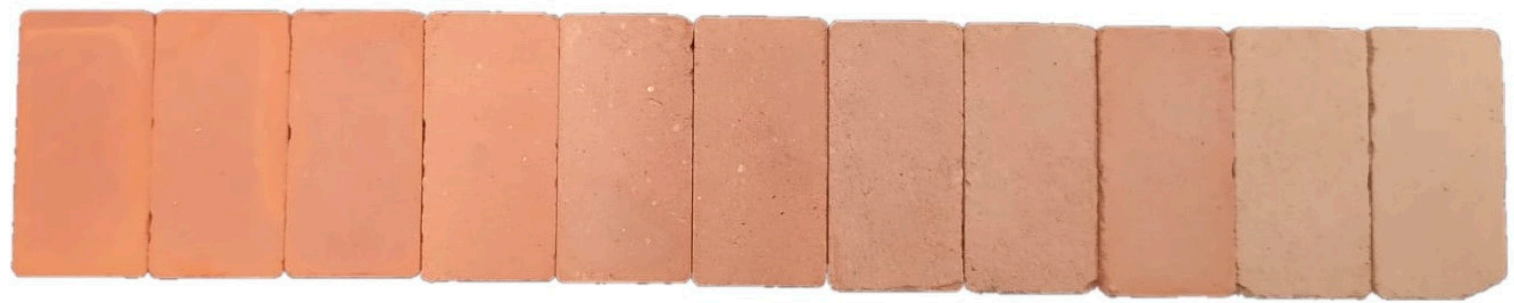

Figure 4. Image of a sample of each family of ceramics made from stone cutting sludge. From left to right, 0S10C, 1S0C, 2S8C, 3S7C, 4S6C, 5S5C, 6S4C, 7S3C, 8S2C, 9S2C, and 10S0C.

The brightness of the image of ceramic products is influenced by the ratio $\left(\mathrm{Fe}_{2} \mathrm{O}_{3}+\mathrm{TiO}_{2}\right) / \mathrm{CaO}$. As the values of this ratio increase, there is a decrease in the luminosity, which is associated with an increase in the number of coloring oxides in the mass. The content of iron oxide in granite sludge is almost twice less than in clays. As the proportion of granite sludge in the composition of the samples increases, the $\mathrm{Fe}_{2} \mathrm{O}_{3}$ content decreases, which leads to a lighter image of the samples.

The red hue of color is influenced by the ratio $\left(\mathrm{CaO}+\mathrm{TiO}_{2}\right) / \mathrm{Fe}_{2} \mathrm{O}_{3}$, with increasing values of this ratio, the share of the red component in the color of the products decreases. This we can see in Figure 4. Mixing clay with granite sludge, we can change the color of the final product. 
In interest to determine the color in a subjective way, and to be able to reproduce it by graphic means, the coordinates in the primary colors (red, green, and blue) of each family of samples are presented below, Table 5 .

Table 5. Color coordinates of the samples families in the primary colors (red, green, and blue).

\begin{tabular}{cccc}
\hline Samples Groups & Red & Green & Blue \\
\hline 0S10C & $355 \pm 10$ & $189 \pm 7$ & $133 \pm 4$ \\
1S9C & $360 \pm 10$ & $204 \pm 4$ & $143 \pm 5$ \\
2S8C & $376 \pm 8$ & $219 \pm 8$ & $157 \pm 6$ \\
3S7C & $437 \pm 17$ & $257 \pm 9$ & $177 \pm 6$ \\
4S6C & $444 \pm 16$ & $282 \pm 8$ & $207 \pm 6$ \\
5S5C & $446 \pm 16$ & $289 \pm 9$ & $216 \pm 5$ \\
6S4C & $474 \pm 15$ & $342 \pm 9$ & $268 \pm 10$ \\
7S3C & $482 \pm 15$ & $342 \pm 12$ & $265 \pm 11$ \\
8S2C & $496 \pm 16$ & $359 \pm 13$ & $281 \pm 11$ \\
9S1C & $532 \pm 18$ & $403 \pm 10$ & $321 \pm 12$ \\
10S0C & $548 \pm 18$ & $424 \pm 11$ & $341 \pm 7$ \\
\hline
\end{tabular}

\subsection{Compressive Strength Test}

The compressive strength test for ceramic materials intended for brick manufacture is essential to corroborate the suitability of the manufactured ceramic. The compressive strength of the brick is one of the limiting factors that will reflect the maximum percentage of stone cutting sludges addition allowed in the ceramic material. The results of the compressive strength tests of the different groups of ceramic samples are represented in Figure 5 graphically, showing the ultimate strength value and deformation values with respect to the percentage of stone cutting sludges in the ceramic.

Figure 5 clearly reflects how a progressive decrease in compressive strength occurs with the increase in the percentage of stone cutting sludges in the ceramic. This was to be expected from the reflected values of density and porosity shown above. A lower density value and higher porosity of the material, under equal conditions and in most cases, corresponds to a lower value of compressive strength. The decrease in compressive strength derives from the higher processing temperature of the chemical compounds present in the granite from which the cutting sludges are derived. Even having a particle size similar to that of clay and a chemical composition quite similar, the sintering temperature of $950^{\circ} \mathrm{C}$ does not cause the same effect in granite cutting sludges as in clay, providing an internal structure with greater porosity and a greater number of connected pores that directly affects the compressive strength. However, the results of ceramics with up to $70 \%$ stone cutting sludges reflect acceptable results according to this test and are therefore feasible to manufacture. In addition, the incorporation of up to $70 \%$ of stone cutting sludges creates particular characteristics that are very interesting for its use, such as lower density and higher porosity. Both factors have a significant influence on the expected thermal and acoustic insulation properties, which are highly desired by the ceramic industry. Its lower density makes it possible to create a lighter material, which with the incorporation of waste, achieves acceptable properties and a lower weight, so as not to overload the structure of the building.

On the other hand, the deformation up to the collapse of the material, i.e., the deformation corresponding to the breaking strain, reflects a progressive decrease with respect to the percentage of added stone cutting sludges. Therefore, the conformed ceramic material with the addition of stone cutting sludges is more brittle. This characteristic, as expected, is not limited by the regulations, but if it is interesting to know it in order to understand the behavior of the waste in the material and the process that has taken place.

It is essential to highlight that in this study, waste, which is an environmental problem, has been incorporated in a material in a percentage of up to $70 \%$, and acceptable results have been obtained for physical and mechanical properties. 

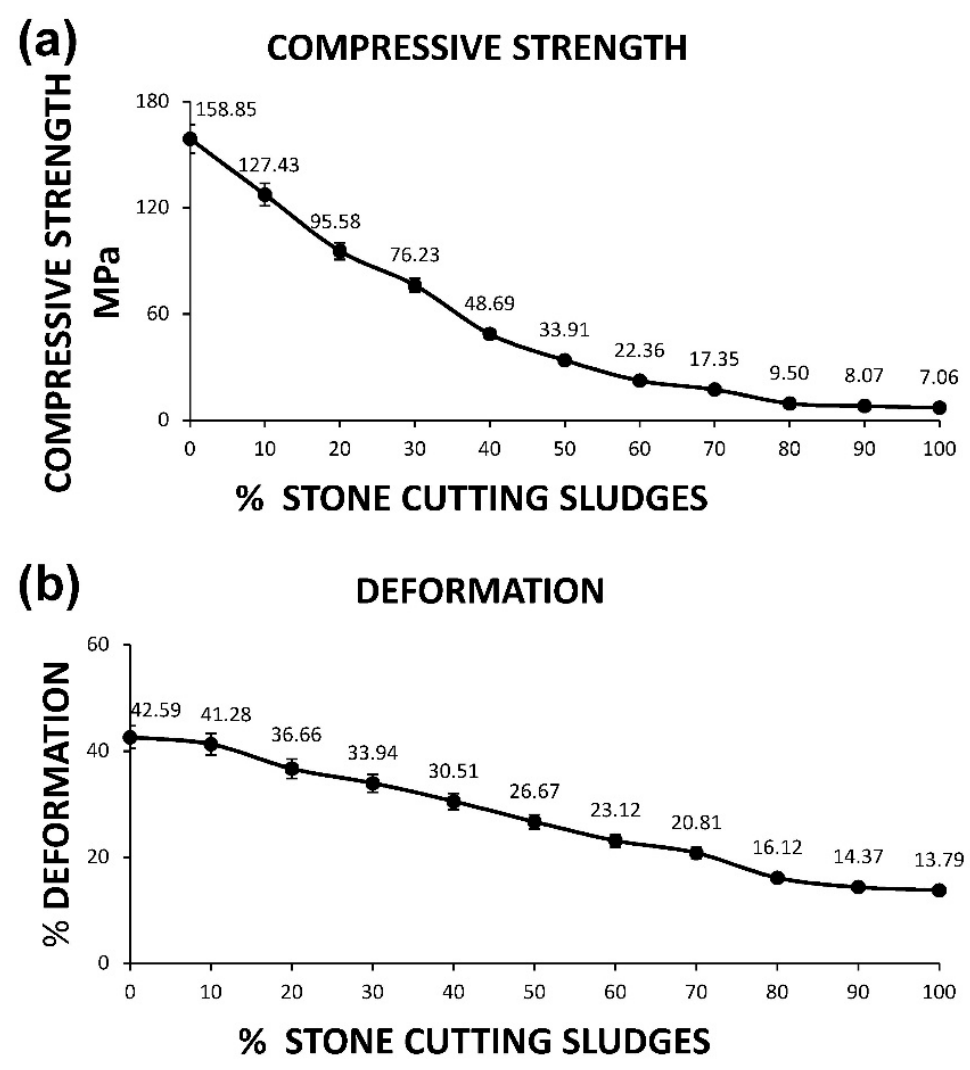

Figure 5. Graphs of the compressive strength test of the different groups of ceramic samples as a function of the percentage of stone cutting sludges. (a) Compressive strength and (b) deformation before material collapse.

\section{Conclusions}

This section first describes the partial conclusions obtained from the various tests in order to evaluate the final conclusion-the possibility of creating ceramic materials for bricks with the incorporation of stone cutting sludges, and with acceptable properties. At the same time, it is important to highlight the importance of incorporating waste, without use, and which represents a serious environmental problem, in a product produced in large quantities, and which contributes particular characteristics to the final product. The partial conclusions are described below:

- stone cutting sludges of granite cutting reflects a density similar to that of clay, which favors the mixed process and therefore its reuse. The density obtained reflects that there are no high proportions of heavy metals derived from the diamond cutting disc that they could become an environmental problem;

- the index of plasticity, which is lower than that of clay, reflects the fact that stone cutting sludges, even if it has a particle size similar to clay, does not have a similar specific surface area and, in turn, does not have secondary problems of expansiveness;

- the chemical analysis of the stone cutting sludges shows mainly the low percentage of carbon. This value reflects the absence of lubricants or fats from of the cutting process, as well as the absence of organic matter or carbonates;

- the X-ray fluorescence of the stone sludges reflects a chemical composition similar to clay and derived from the composition of granite (quartz, feldspars, and mica) without the existence of contamination with heavy metals or chemical elements, such as sulfur and chlorine, which could pose an environmental problem;

- the loss on ignition details the higher transformation temperature of the chemical compounds present in the stone cutting sludges with respect to the clay. Low percentage of loss weight is 
reflected in the test that were confirmed by the loss weight of the ceramic samples with different percentages of stone cutting sludges;

- linear shrinkage of ceramic samples is less, and even dilatation occurs, for ceramics with stone cutting sludges. Therefore, the assumptions induced in the characterization about the behavior of stone cutting sludges in the sintering process are demonstrated;

- capillarity water absorption and cold water absorption increases with the increase in the percentage of stone cutting sludges, reflecting a more open structure with a greater number of pores. This characteristic is especially suitable about thermal and acoustic insulators materials;

- the porosity of the samples increases as the percentage of stone cutting sludges increases, as confirmed by the above tests. In relation to this fact, the density of the ceramic obtained decreases with the increase in the percentage of stone cutting sludges. This lower density produces a more open and porous structure of the ceramic with stone cutting sludges, which provides a lighter material for construction;

- the color of the ceramics varies with the percentage of stone cutting sludge; however, all ceramics show similar tonalities and progressive changes in brightness and color;

- the compressive strength test reflects a decrease in strength with an increase in the percentage of stone cutting sludges, obviously brought about by the above characteristics. The maximum addition of stone cutting sludges for the manufacture of brick ceramics is $70 \%$, achieving rejectable values of strength for higher percentages of incorporation.

Based on the partial conclusions, it can be stated that it is possible to incorporate stone cutting sludges from granite in ceramic materials for brick manufacturing, in percentages of up to $70 \%$. With this research, therefore, a sustainable material is obtained, which reduces the deposition of waste, such as stone cutting sludges in landfill, which avoids environmental pollution due to its deposit, and creates a material with acceptable characteristics (and also has particulars characteristics). It is therefore an ideal solution for the reuse of stone cutting sludge as opposed to other solutions currently being proposed, for various reasons. These reasons are mainly: the ease with which the waste can be incorporated into the industrial process for the manufacture of new ceramics, the reduction of the extraction of virgin materials (clay) and the elimination of waste disposal in landfills. Furthermore, the presence, which is not the case in this study, of heavy metals, could be retained in the ceramic matrix, avoiding future problems of contamination due to leaching of the waste in its deposit.

Author Contributions: Conceptualization, F.A.C.-I., J.M.T.-S., J.S.-M., V.K. and V.S.; methodology, F.A.C.-I., J.M.T.-S., J.S.-M., V.K. and V.S.; software, J.M.T.-S., J.S.-M. and V.S.; validation, F.A.C.-I. and V.K.; formal analysis, F.A.C.-I. and V.K.; investigation, J.M.T.-S., J.S.-M. and V.S.; resources, F.A.C.-I.; data curation, V.S.; writing-original draft preparation, J.S.-M.; writing—review and editing, J.M.T.-S.; visualization, J.M.T.-S.; supervision, F.A.C.-I. and V.K.; project administration, J.S.-M. and V.S.; funding acquisition, F.A.C.-I. All authors have read and agreed to the published version of the manuscript.

Funding: This research received no external funding.

Acknowledgments: Technical and human support provided by CICT of Universidad de Jaén (UJA, MINECO, Junta de Andalucía, FEDER) is gratefully acknowledged.

Conflicts of Interest: The authors declare no conflict of interest.

\section{References}

1. Aznar-Sánchez, J.A.; García-Gómez, J.J.; Velasco-Muñoz, J.F.; Carretero-Gómez, A. Mining waste and its sustainable management: Advances in worldwide research. Minerals 2018, 8, 284. [CrossRef]

2. Tayebi-Khorami, M.; Edraki, M.; Corder, G.; Golev, A. Re-Thinking Mining Waste through an Integrative Approach Led by Circular Economy Aspirations. Minerals 2019, 9, 286. [CrossRef]

3. Almeida, M.I.; Dias, A.C.; Demertzi, M.; Arroja, L. Contribution to the development of product category rules for ceramic bricks. J. Clean. Prod. 2015, 92, 206-215. [CrossRef]

4. Zhang, L.; Liu, B.; Du, J.; Liu, C.; Wang, S. $\mathrm{CO}_{2}$ emission linkage analysis in global construction sectors: Alarming trends from 1995 to 2009 and possible repercussions. J. Clean. Prod. 2019, 221, 863-877. [CrossRef] 
5. Subashi De Silva, G.H.M.J.; Mallwattha, M.P.D.P. Strength, durability, thermal and run-off properties of fired clay roof tiles incorporated with ceramic sludge. Constr. Build. Mater. 2018, 179, 390-399. [CrossRef]

6. Liu, B.; Zhang, L.; Sun, J.; Wang, D.; Liu, C.; Luther, M.; Xu, Y. Composition of energy outflows embodied in the gross exports of the construction sector. J. Clean. Prod. 2020, 248, 119296. [CrossRef]

7. Binici, H.; Aksogan, O.; Shah, T. Investigation of fibre reinforced mud brick as a building material. Constr. Build. Mater. 2005, 19, 313-318. [CrossRef]

8. Abbas, S.; Saleem, M.A.; Kazmi, S.M.S.; Munir, M.J. Production of sustainable clay bricks using waste fly ash: Mechanical and durability properties. J. Build. Eng. 2017, 14, 7-14. [CrossRef]

9. Shakir, A.; Shakir, A.A.; Mohammed, A.A. Manufacturing of Bricks in the Past, in the Present and in the Future: A state of the Art Review. Int. J. Adv. Appl. Sci. 2013, 2, 145-156. [CrossRef]

10. Murmu, A.L.; Patel, A. Towards sustainable bricks production: An overview. Constr. Build. Mater. 2018, 165, 112-125. [CrossRef]

11. Gavali, H.R.; Ralegaonkar, R.V. Design of eco-efficient housing with sustainable alkali-activated bricks. J. Clean. Prod. 2020, 254, 120061. [CrossRef]

12. Baghel, R.; Pandel, U.; Vashistha, A. Manufacturing of sustainable bricks: Utilization of mill scale and marble slurry. Mater. Today Proc. 2020, 26, 2136-2139. [CrossRef]

13. Lingling, X.; Wei, G.; Tao, W.; Nanru, Y. Study on fired bricks with replacing clay by fly ash in high volume ratio. Constr. Build. Mater. 2005, 19, 243-247. [CrossRef]

14. Singh, S.; Aswath, M.U.; Ranganath, R.V. Performance assessment of red mud based geopolymer bricks and prisms. J. Build. Eng. 2020, 101462. [CrossRef]

15. Zhang, Z.; Wong, Y.C.; Arulrajah, A.; Horpibulsuk, S. A review of studies on bricks using alternative materials and approaches. Constr. Build. Mater. 2018, 188, 1101-1118. [CrossRef]

16. Muñoz Velasco, P.; Morales Ortíz, M.P.; Mendívil Giró, M.A.; Muñoz Velasco, L. Fired clay bricks manufactured by adding wastes as sustainable construction material-A review. Constr. Build. Mater. 2014, 63, 97-107. [CrossRef]

17. Gupta, V.; Chai, H.K.; Lu, Y.; Chaudhary, S. A state of the art review to enhance the industrial scale waste utilization in sustainable unfired bricks. Constr. Build. Mater. 2020, 254, 119220. [CrossRef]

18. Zhang, L. Production of bricks from waste materials-A review. Constr. Build. Mater. 2013, 47, $643-655$. [CrossRef]

19. Fiala, L.; Konrád, P.; Fořt, J.; Keppert, M.; Černý, R. Application of ceramic waste in brick blocks with enhanced acoustic properties. J. Clean. Prod. 2020, 261, 121185. [CrossRef]

20. Ozturk, S.; Sutcu, M.; Erdogmus, E.; Gencel, O. Influence of tea waste concentration in the physical, mechanical and thermal properties of brick clay mixtures. Constr. Build. Mater. 2019, 217, 592-599. [CrossRef]

21. Taurino, R.; Ferretti, D.; Cattani, L.; Bozzoli, F.; Bondioli, F. Lightweight clay bricks manufactured by using locally available wine industry waste. J. Build. Eng. 2019, 26, 100892. [CrossRef]

22. Eliche-Quesada, D.; Martínez-García, C.; Martínez-Cartas, M.L.; Cotes-Palomino, M.T.; Pérez-Villarejo, L.; Cruz-Pérez, N.; Corpas-Iglesias, F.A. The use of different forms of waste in the manufacture of ceramic bricks. Appl. Clay Sci. 2011, 52, 270-276. [CrossRef]

23. Singh, A.; Berghorn, G.; Joshi, S.; Syal, M. Review of life-cycle assessment applications in building construction. J. Archit. Eng. 2011, 17, 15-23. [CrossRef]

24. Ter Teo, P.; Anasyida, A.S.; Kho, C.M.; Nurulakmal, M.S. Recycling of Malaysia's EAF steel slag waste as novel fluxing agent in green ceramic tile production: Sintering mechanism and leaching assessment. J. Clean. Prod. 2019, 241, 118144. [CrossRef]

25. Cusidó, J.A.; Cremades, L.V. Environmental effects of using clay bricks produced with sewage sludge: Leachability and toxicity studies. Waste Manag. 2012, 32, 1202-1208. [CrossRef]

26. Mao, L.; Guo, H.; Zhang, W. Addition of waste glass for improving the immobilization of heavy metals during the use of electroplating sludge in the production of clay bricks. Constr. Build. Mater. 2018, 163, 875-879. [CrossRef]

27. Graziani, A.; Giovannelli, G. I Lapidei Struttura del Settore e Tendenze Innovative; Centro Studi Fillea: Rome, Italy, 2015; Available online: http://www.filleacgil.it/nazionale/accordi/all_1817.pdf (accessed on 10 June 2020). (In Italian)

28. Zichella, L.; Bellopede, R.; Spriano, S.; Marini, P. Preliminary investigations on stone cutting sludge processing for a future recovery. J. Clean. Prod. 2018, 178, 866-876. [CrossRef] 
29. Dino, G.A.; Fornaro, M.; Corio, E.; Fornaro, E. Residual sludge management: A possible reuse as loam. In Proceedings of the 10th IAEG Congress, Nottingham, UK, 6-10 September 2006; pp. 6-8.

30. Montanari, E. Una particolare categoria di rifiuti provenienti da attività estrattiva: I limi di lavaggio inerti-Problematiche inerenti e quadro normativo. J. Ord. Geol. Emilia-Romagna 2007, 27, 31-36. Available online: http://www.geologiemiliaromagna.it/rivista/2007-27_Montanari.pdf (accessed on 15 June 2020). (In Italian).

31. Nasserdine, K.; Mimi, Z.; Bevan, B.; Elian, B. Environmental management of the stone cutting industry. J. Environ. Manag. 2009, 90, 466-470. [CrossRef]

32. Mancini, R.; Fornaro, M.; Dino, G.A. Applicazioni e Trattamenti in Campo Ingegneristico e Industriale; Politecnico di Torino: Torino, Italy, 2005; Available online: http://www.naturalstoneinfo.com/download/interregIII.03.pdf (accessed on 15 June 2020). (In Italian)

33. EUR-Lex-31999L0031-EN-EUR-Lex. Available online: https://eur-lex.europa.eu/legal-content/EN/TXT/ ?uri=CELEX\%3A31999L0031 (accessed on 9 May 2020).

34. Aliabdo, A.A.; Abd Elmoaty, A.E.M.; Auda, E.M. Re-use of waste marble dust in the production of cement and concrete. Constr. Build. Mater. 2014, 50, 28-41. [CrossRef]

35. Mashaly, A.O.; Shalaby, B.N.; Rashwan, M.A. Performance of mortar and concrete incorporating granite sludge as cement replacement. Constr. Build. Mater. 2018, 169, 800-818. [CrossRef]

36. Mashaly, A.O.; El-Kaliouby, B.A.; Shalaby, B.N.; El-Gohary, A.M.; Rashwan, M.A. Effects of marble sludge incorporation on the properties of cement composites and concrete paving blocks. J. Clean. Prod. 2016, 112, 731-741. [CrossRef]

37. Lozano-Lunar, A.; Dubchenko, I.; Bashynskyi, S.; Rodero, A.; Fernández, J.M.; Jiménez, J.R. Performance of self-compacting mortars with granite sludge as aggregate. Constr. Build. Mater. 2020, 251, 118998. [CrossRef]

38. Sardinha, M.; de Brito, J.; Rodrigues, R. Durability properties of structural concrete containing very fine aggregates of marble sludge. Constr. Build. Mater. 2016, 119, 45-52. [CrossRef]

39. Nascimento, A.S.S.; Santos, C.P.; Melo, F.M.C.; Oliveira, V.G.A.; Betânio Oliveira, R.M.P.; Macedo, Z.S.; Oliveira, H.A. Production of plaster mortar with incorporation of granite cutting wastes. J. Clean. Prod. 2020, 265, 121808. [CrossRef]

40. Chang, F.C.; Lee, M.Y.; Lo, S.L.; Lin, J.D. Artificial aggregate made from waste stone sludge and waste silt. J. Environ. Manag. 2010, 91, 2289-2294. [CrossRef]

41. Choudhary, J.; Kumar, B.; Gupta, A. Feasible utilization of waste limestone sludge as filler in bituminous concrete. Constr. Build. Mater. 2020, 239, 117781. [CrossRef]

42. Li, L.G.; Zhuo, Z.Y.; Kwan, A.K.H.; Zhang, T.S.; Lu, D.G. Cementing efficiency factors of ceramic polishing residue in compressive strength and chloride resistance of mortar. Powder Technol. 2020, 367, 163-171. [CrossRef]

43. Fedorenko, O.Y.; Schukina, L.P.; Rishchenko, M.I.; Jury, L.V. Clinker Ceramic Materials Based on Natural and Man-made Raw Materials of Ukraine; Gevorkyan, E.S., Shabanova, G.N., Eds.; National Technical University "Kharkiv Polytechnic Institute": Kharkiv, Ukraine, 2018; Available online: http://repository.kpi.kharkov.ua/ bitstream/KhPI-Press/38788/1/Book_2018_Fedorenko_Klinkerni_keramichni.pdf (accessed on 10 June 2020). (In Ukrainian)

(C) 2020 by the authors. Licensee MDPI, Basel, Switzerland. This article is an open access article distributed under the terms and conditions of the Creative Commons Attribution (CC BY) license (http://creativecommons.org/licenses/by/4.0/). 